\title{
An autopsy case of epignathus (immature teratoma of the soft palate) with intracranial extension but without brain invasion: case report and literature review
}

\author{
Mari Kirishima ${ }^{1,2^{*}}$ (D) Sohsuke Yamada ${ }^{3}$, Mitsuhisa Shinya ${ }^{4}$, Shun Onishi ${ }^{5}$, Yuko Goto ${ }^{1}$, Ikumi Kitazono ${ }^{1}$, Tsubasa Hiraki ${ }^{2}$,
} Michiyo Higashi', Akira I. Hida ${ }^{1}$ and Akihide Tanimoto ${ }^{1}$

\begin{abstract}
Background: Epignathus is a rare congenital orofacial teratoma infrequently associated with intracranial extension. Intracranial extension of an epignathus indicates a poor prognosis; however, only a small number of such cases have been reported. While there have been some studies reporting cases of epignathus expanding directly into the cranium, others have reported no communication between an epignathus and an intracranial tumor.

Case presentation: A fetus at gestational week 27 was suspected of having an epignathus with intracranial tumor as shown by ultrasonographic and magnetic resonance imaging. The fetus was stillborn and an autopsy was performed. An epignathus measuring $12 \times 6 \times 6 \mathrm{~cm}$ and weighing $270 \mathrm{~g}$ protruded from the mouth, with its base on the soft palate. An intracranial tumor weighing $14 \mathrm{~g}$ was located at the middle intracranial fossa and connected to the epignathus through the right side of the sella turcica. The intracranial tumor was encapsulated, and there was no invasion into the brain. Histologically, both the epignathus and intracranial tumor were immature teratomas, with neural and pulmonary components that were especially immature as compared to those of the internal organs and brain tissues of the fetus.

Conclusion: There have been several reports of epignathus and intracranial tumors that did not communicate; therefore, careful evaluation is needed when a fetus is suspected of having an epignathus extending into an intracranial lesion. Our case supports the findings that an epignathus can directly expand into the cranium. Moreover, this is a rare case of an epignathus in which the intracranial lesion was encapsulated and did not invade the brain. These rare but important findings will provide additional, potential therapeutic strategies for gynecologists, neurosurgeons, and pathologists.
\end{abstract}

Keywords: Epignathus, Intracranial extension, Immature teratoma, Hypoxia

\section{Background}

Here we report a prenatal case of an epignathus with intracranial extension, pathologically confirmed at autopsy. An epignathus is a rare congenital orofacial teratoma found in approximately 1:35,000-1:200,000 live births, accounting for $2-9 \%$ of all teratomas $[1,2]$. In $6 \%$ of all the cases,

\footnotetext{
* Correspondence: k3324879@kadai.jp

'Department of Pathology, Field of Oncology, Graduate School of Medical and Dental Sciences, Kagoshima University, 8-35-1 Sakuragaoka, Kagoshima 890-8544, Japan

²Department of Pathology, Kagoshima University Hospital, 8-35-1

Sakuragaoka, Kagoshima 890-8544, Japan

Full list of author information is available at the end of the article
}

teratomas are associated with malformations such as cleft palate, bifid tongue, and bifid uvula [1, 3]. Since epignathus fills the mouth and often protrudes outside, fatal airway obstruction frequently occurs. Prenatal detection allows an obstetrics team to schedule an elective cesarean delivery. Early intervention for ventilation is necessary, and immediate tracheostomy is often required. An epignathus is infrequently associated with an intracranial extension. Prenatal intracranial tumors include a variety of neoplasms, such as teratomas, neuroepithelial tumors, and craniopharyngiomas [4]. Prenatal intracranial teratomas have been reported to result in a poor prognosis $[4,5]$, and the clinical outcome

(C) The Author(s). 2018 Open Access This article is distributed under the terms of the Creative Commons Attribution 4.0 International License (http://creativecommons.org/licenses/by/4.0/), which permits unrestricted use, distribution, and 
of epignathus with intracranial extension remains unclear. Therefore, evaluating whether an epignathus extends into the cranium, whether the intracranial lesion and epignathus have different etiologies, and whether the intracranial tumor is invading the brain are crucial determinations in order to improve the prognosis of such cases.

\section{Case presentation}

A 32-year-old woman, 3G2P (2 normal vaginal delivery, no abnormality) was referred to our hospital at 25 weeks of gestation for evaluation of a tumorous lesion located near the neck of the fetus, which was detected at gestational week 23. Prenatal three-dimensional ultrasonography performed at gestational week 25 showed a giant tumor around the neck and face (Fig. 1a). The spatial relationship between the tumor and the oral cavity was not confirmed; however, the possibility of an epignathus was strongly suspected. A prenatal ultrasound at gestational week 26 revealed a polyhydramnios, a giant tumor around the neck, and an intracranial tumorous lesion (Fig. 1b). Color Doppler ultrasonography showed arterial branches assumedly from the right internal carotid artery running into the giant tumor around the neck. Arterial branches from the right middle cerebral artery were suspected to be running into the intracranial lesion. These potential feeding arteries were of concern, because they could raise difficulties in the control of bleeding during an ex utero intrapartum treatment
(EXIT) procedure. Magnetic resonance imaging (MRI) performed at gestational week 25 showed a giant tumor around the neck with heterogeneous iso-to-low signal density on T1-weighted images, and iso-to-high signal density on T2-weighted images. MRI also suggested a connection between the giant tumor and the intracranial lesion (Fig. 1c). An epignathus with intracranial extension was suspected. The possibility of preterm labor was a concern; therefore, supportive care with amnioreduction was to be provided until the fetus attained a certain weight and stage of organ development for performance of a cesarean delivery, at approximately 30 gestational weeks. At gestational week 27, after the amnioreduction was performed, a placental abruption occurred, and the fetus was delivered by emergency cesarean section. Chromosome analysis was not performed. The fetus was stillborn, and an autopsy was performed after $27 \mathrm{~h}$, for pathological diagnosis and assessment of the intracranial lesion.

The fetus weighed $1228 \mathrm{~g}$. At dissection, an epignathus was observed protruding from the mouth (Fig. 2a). It was a large, reddish, multicystic tumor measuring $12 \times$ $6 \times 6 \mathrm{~cm}$ and weighing $270 \mathrm{~g}$. Neither a cleft palate nor cleft lips were found; however, there was a defect in the soft palate, within which the base of the epignathus was located (Fig. 2b). Upon opening the skull, an intracranial tumor weighing $14 \mathrm{~g}$ was detected in the middle cranial fossa. It was covered by a thin capsule, and there was no
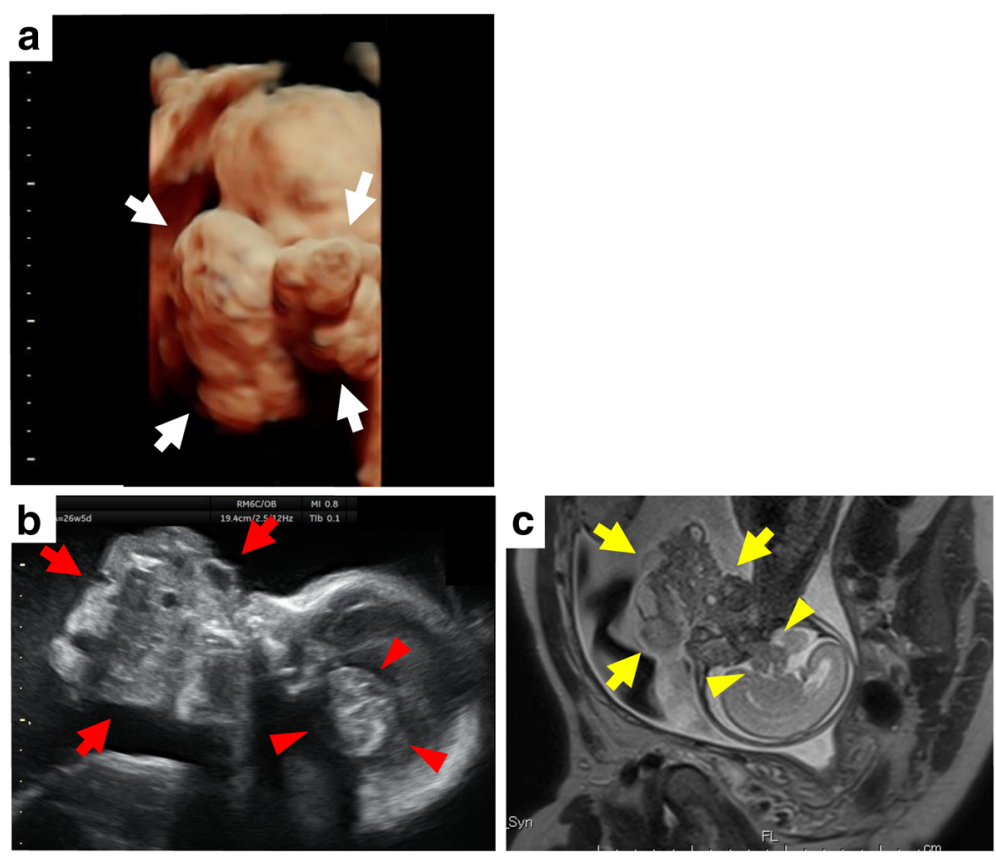

Fig. 1 Ultrasonographic and MRI images. a Three-dimensional ultrasonographic image at gestational week 25 shows a giant tumor around the neck and face (white arrow), strongly suggesting an epignathus. b Ultrasonographic image at gestational week 26 shows a giant tumor around the neck (red arrow), and an intracranial tumorous lesion (red arrowhead). c MRI image at gestational week 25 suggests a connection between the giant tumor around the neck (yellow arrow) and the intracranial tumor (yellow arrowhead) 

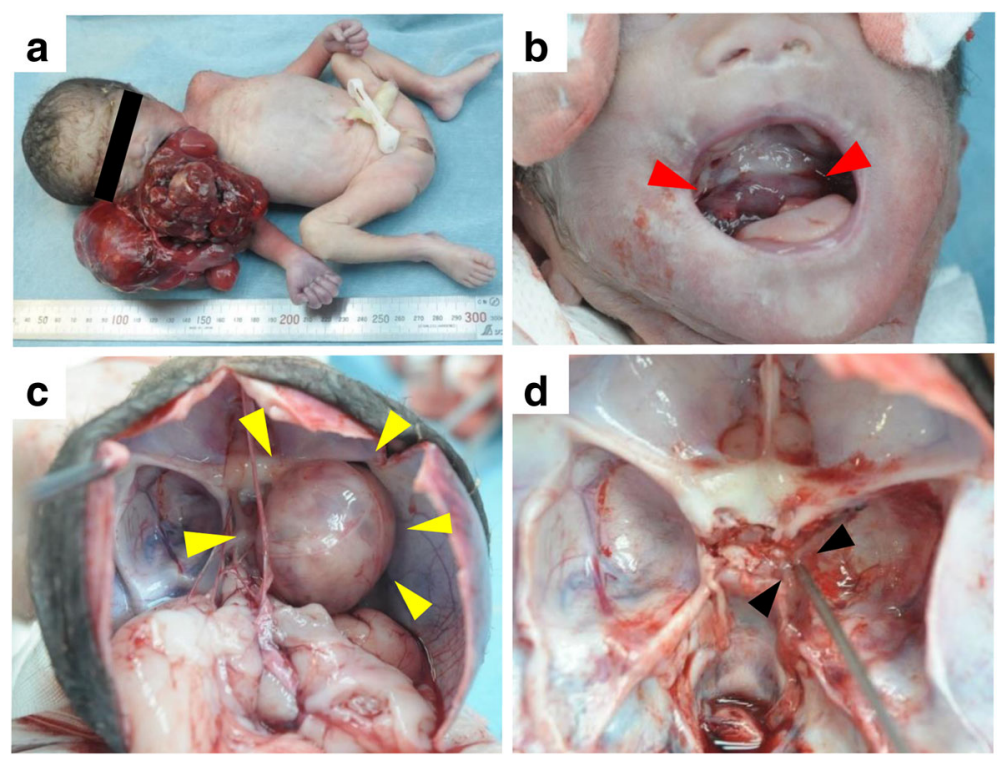

Fig. 2 Macroscopic findings at autopsy. a The epignathus, a large reddish multicystic tumor is seen protruding from the mouth. $\mathbf{b}$ There is a defect in the soft palate within which the base of the epignathus is located (red arrowhead). $\mathbf{c}$ The intracranial tumor is covered by a thin capsule (yellow arrowhead) and there is no invasion of the brain. $\mathbf{d}$ After removal of the stem of the intracranial tumor, a small hole, measuring $2 \mathrm{~mm}$ in diameter, is detected on the right side of the sella turcica. A communication can be seen between the epignathus and the intracranial tumor through this hole (black arrowhead)

invasion into the brain (Fig. 2c). The tumor had a very short stem, $2 \mathrm{~mm}$ in diameter, which was located on the right side of the sella turcica. There was no tumor involvement in the optic foramen, foramen ovale, or optic nerve. After removal of the upper portion of the tumor above the stem, a small hole was found, measuring 2 $\mathrm{mm}$ in diameter, at the base of the sella turcica (Fig. 2d). To avoid facial and cranial deformation, in consideration of the distress of the bereaved family, we did not make further incisions through the bone, but rather, confirmed the continuance of the epignathus and intracranial tumor by using a sonde. The spreading of the epignathus into the cranium was consistent with the clinical ultrasonographic evaluation.

Macroscopically, the epignathus was a large multicystic tumor, containing white solid parts and cysts filled with serous or bloody fluid (Fig. 3a-c). Calcification was also seen. Microscopically, the prominent component of the tumor was immature neuroepithelial tissue (Fig. 4a). Immature neural tubules were seen, lined by dark hyperchromatic columnar cells with stratification and frequent mitoses, and were accompanied by glial tissue. Other components included melanocytes, retinal tissue, exocrine glands, skin, hepatocytes, renal glomeruli, lung tissue, glandular epithelium with goblet cells, squamous epithelium, cartilage, bone, adipose tissue, and smooth muscle (Fig. 4b-d).

The intracranial tumor was macroscopically white and soft (Fig. 3d). The thin capsule was ruptured while we were excising the tumor at autopsy. Microscopically, the majority of the tumor was immature neuroepithelial tissue (Fig. 5a). The main components were immature neural tubules lined by dark hyperchromatic columnar cells with stratification and mitoses, and were accompanied by glial tissue. Other components included choroid plexus, aggregation of hepatocytes with extramedullary hematopoiesis, exocrine glands resembling pancreatic acini, columnar glandular cells resembling gastric foveolar epithelium, squamous epithelium, cartilage, and calcification (Fig. 5b-d).

The main components of the oral and intracranial tumors are summarized in Table 1.

Both the epignathus and intracranial lesion were composed of three germinal layers, with immature neuroepithelial tissue being the most predominant. Pulmonary components seen in the epignathus were equivalent to a canalicular stage of development, which was immature as compared to the saccular stage of the fetus's internal lungs (Fig. 6). We, therefore, made the diagnosis of epignathus with intracranial extension, histologically showing immature teratoma.

As for the internal organs of the fetus, histological findings associated with hypoxia were seen. There was a great increase in weight seen in the liver and adrenal glands. Histologically, the liver showed congestion and marked hematopoiesis. Erythropoiesis usually diminishes and myelopoiesis becomes only faintly apparent in the liver by 28 weeks [6]; however, in our case, both erythropoiesis and myelopoiesis were marked in the liver as well 

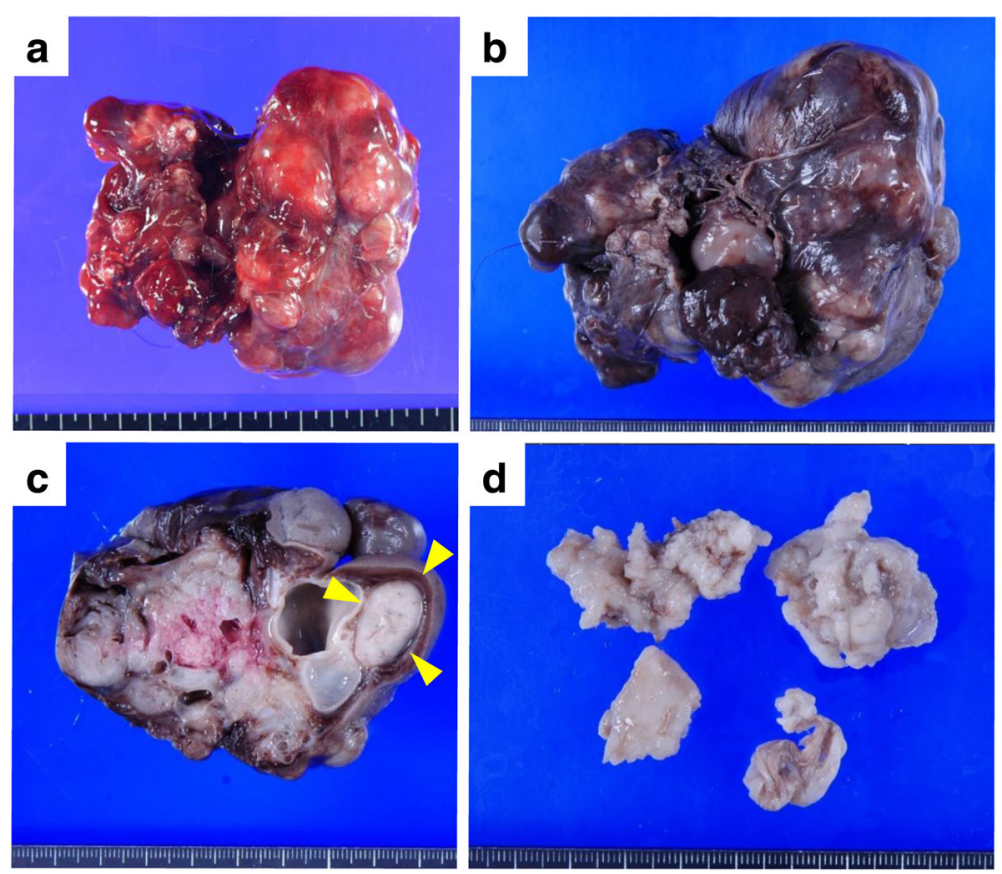

Fig. 3 Macroscopic images of the epignathus. a At autopsy, the epignathus is a large reddish multicystic tumor. b After formalin fixation, the epignathus is seen as a dark-brown-colored tumor and cysts containing serous or bloody fluids. $\mathbf{c}$ The cut section shows whitish solid parts and cysts. A small component resembling a lung is seen (arrowhead). $\mathbf{d}$ The intracranial tumor is white and soft

as in the spleen. Furthermore, increased hemosiderin deposition was seen, not only within the periportal spaces, but also in surrounding hepatocytes. The cortices of both adrenal glands showed adenoid changes, with focal hemorrhaging. These findings in the liver and adrenal glands indicate hypoxic stress. The lungs weighed a little less than is typical with respect to the gestational week; however, histologically they had developed into the saccular stage. Because the kidneys and lungs were in the normal stage of development, the fetus could have swallowed some amniotic fluid in utero in spite of having the epignathus. Altogether, above-mentioned
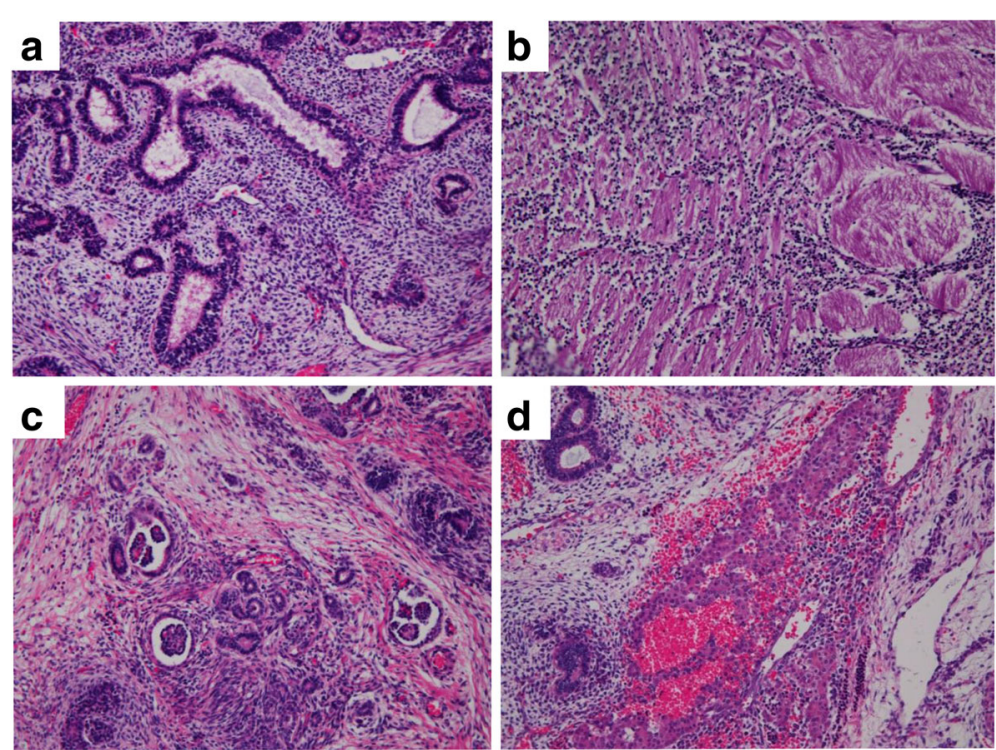

Fig. 4 Microscopic images of tridermal components in the epignathus. a Immature neural tubules (hematoxylin and eosin [HE] stain, $\times 100)$. b Smooth muscle (HE stain, $\times 100)$. c Renal glomeruli (HE stain, $\times 100)$. d Hepatocytes (HE stain, $\times 100)$ 


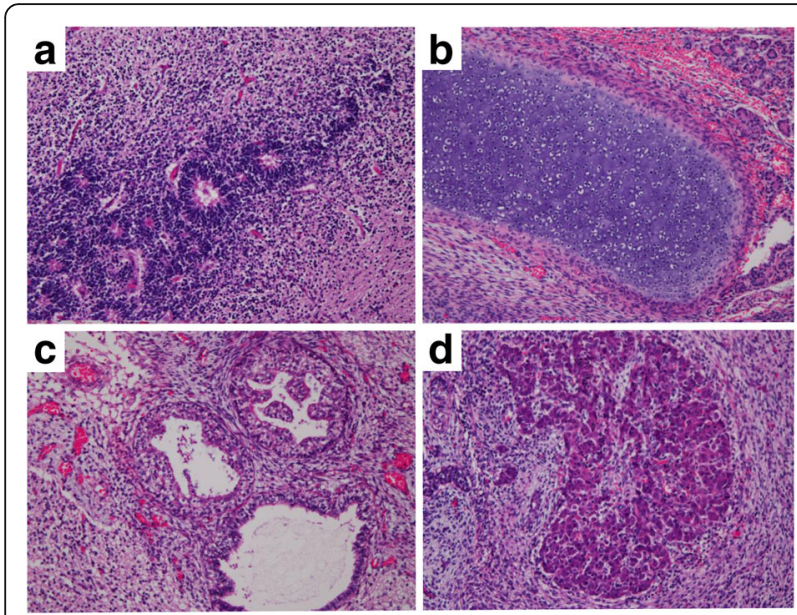

Fig. 5 Microscopic images of tridermal components in the intracranial tumor. a Immature neural tubules (hematoxylin and eosin [HE] stain, $\times 100)$. b Cartilage (HE stain, $\times 100$ ). c Esophagus (HE stain, $\times 100)$. $\mathbf{d}$ Hepatocytes (HE stain, $\times 100)$

findings support the determination that an airway obstruction induced by the epignathus was the direct cause of death. The remainder of the detected organs (heart, thymus, gastrointestinal tract, gallbladder, pancreas, uterus, and ovaries) had developed sufficiently for the gestational week. The weight of the organs with means and standard deviations [7] are shown in Table 2. The placenta weighed $840 \mathrm{~g}$ and was histologically normal, except for the retroplacental hematoma, which was consistent with the clinical episode of placental abruption.

\section{Discussion and Conclusions}

An epignathus is a rare congenital orofacial teratoma. In some studies, epignathi have been found to be associated with chromosomal abnormalities, such as duplication of $1 \mathrm{q}$ and 19p [8], ring X chromosome mosaicism [9], and the 49,XXXXY karyotype [10]. However, other studies have reported epignathi with no chromosomal abnormalities $[11,12]$. The parents in our case requested that we not perform chromosome analysis; therefore, we were unable to establish a relationship between the epignathus and the chromosomal karyotype.

An epignathus frequently leads to fatal airway obstruction, so prenatal detection and early intervention to preserve ventilation is necessary. There have only been a few cases of epignathi that have been treated successfully following prenatal diagnosis and early interventions including surgery and chemotherapy. For example, Dapké et al. [11] reported a case with a three-year follow-up, in which prenatal detection was made at gestational week 27, and the fetus was born by cesarean section at gestational week 32 . The patency of the airway was reestablished during delivery and the epignathus was removed immediately afterwards. Histologically, the epignathus was found to be a mature teratoma, and there was no intracranial extension.

Carvalho et al. [13] reported a seven-year follow-up case that also involved an epignathus determined to be a mature teratoma, with no intracranial extension. Carvalho's case was exceptional for two reasons. First, the epignathus was not detected until the fetus was delivered vaginally at gestational week 40 , due to inadequate prenatal care. Secondly, although the epignathus caused feeding problems, it did not obstruct the airway. Surgery to remove the epignathus was performed on postnatal day 14 , and the residual tumor regressed after chemotherapy [13].

In both the cases reported by Dapké et al. [11] and Carvalho et al. [13], the epignathi were mature teratomas, and there was no intracranial extension.

An epignathus is infrequently associated with an intracranial lesion. In such cases, an intracranial teratoma needs to be differentiated from other intracranial tumors. Prenatal intracranial tumors can include a variety of neoplasms, such as teratomas, neuroepithelial tumors, and craniopharyngiomas [4]. It has been reported that prenatal intracranial teratomas typically result in poor prognoses $[4,5]$, and the clinical outcome of epignathus with intracranial extension is, to date, unclear. We were unable to find in the literature a single case of an epignathus with intracranial extension that was histologically determined to be an immature teratoma and was successfully treated with surgery or chemotherapy.

Some cases have been reported as epignathus with intracranial teratoma, and a common site of connection is the sella turcica [14], as seen in our case.

Thirteen cases of epignathus with intracranial tumor have been reported; the clinical and pathological summaries are shown in Table 3, and the earlier cases (18611963) are described in a report by Y. Hosoda [14].

Our case involved the largest epignathus with intracranial extension reported to date. Moreover, this epignathus

Table 1 Components of the epignathus and the intracranial tumor

\begin{tabular}{lll}
\hline & epignathus & intracranial tumor \\
\hline ectoderm & neural tube, glial tissue, retina, melanocytes, skin and appendages, exocrine & neural tube, glial tissue, choroid plexus \\
& glands (resemblings pancreatic tissue) & \\
mesoderm & cartilage, bone, adipose tissue, smooth muscle, vessels & cartilage \\
endoderm & hepatocytes, renal glomeruli, lung, esophagus, gastric mucosa, intestinal mucosa & liver, glandular epithelium, exocrine glands \\
& with goblet cells & (resembling pancreatic tissue) \\
\hline
\end{tabular}


Table 2 Organ weights of the fetus with means and standard deviations [7]

\begin{tabular}{lllllll}
\hline & placenta $[\mathrm{g}]$ & body weight $[\mathrm{g}]$ & $\mathrm{CRL}[\mathrm{cm}]$ & thymus $[\mathrm{g}]$ & heart [g] & lung (bilateral) $[\mathrm{g}]$ \\
Our case & 840 & $1224-280=944$ & 25 & 2.4 & 5.8 & $4.7+6.0=10.7$ \\
means and standard deviations [7] & $240-380$ & $836 \pm 197$ & $24.2 \pm 2.5$ & $2.3 \pm 1.2$ & $5.8 \pm 1.9$ & $22.1 \pm 9.7$ \\
& spleen $[\mathrm{g}]$ & liver $[\mathrm{g}]$ & kidney (bilateral) [g] & adrenal gland (bilateral) [g] & brain [g] \\
Our case & 1.8 & 84.4 & $4.5+4.4=8.9$ & $2.6+2.4=5.0$ & 142.5 \\
means and standard deviations [7] & $1.7 \pm 1.0$ & $35.1 \pm 13.3$ & $8.6 \pm 3.0$ & $2.5 \pm 1.1$ & $118 \pm 21$ \\
\hline
\end{tabular}

was located at the base of the soft palate, and there was a direct invasion into the cranium through the right side of the sella turcica. The intracranial tumor was encapsulated and had not invaded the brain. Histologically, the epignathus and intracranial lesion were composed of cells originating from all three germinal layers. Importantly, the neural and pulmonary components were immature as compared to those of the fetal internal organs and brain tissue. Both shared the same histological features of immature teratomas, and, thus, we made the diagnosis of epignathus with intracranial extension.

Smith et al. [15] and Wang et al. [12] reported cases in which an epignathus had directly invaded the cranium. Within the literature review included in a study by $\mathrm{Y}$, Hosoda [14], one case, reported by Ehrich et al., did not show a direct connection between the epignathus and intracranial lesion; however, brain tissue was seen in the sphenoid bone, which highly suggested a connection between the two lesions. On the other hand, Johnston et al. [16] and Calda et al. [17] reported cases where there were no direct connections between the epignathus and intracranial lesions. Calda et al. reported that an intracranial lesion had been suspected to be an expansion of an epignathus; however, a postmortem MRI and pathologic examination of the fetus confirmed an epignathus with bilateral ventricular dilatation, corpus callosum agenesis, and a neuroepithelial intracranial cyst [17]. While evaluation of an extension of an epignathus and intracranial lesion, including any invasion of the brain, is important, it is difficult to confirm this diagnosis prenatally. There have been cases reported in which an epignathus and intracranial tumor did not communicate directly, which promotes the necessity of careful evaluation when the fetus is suspected of having these lesions. Our case not only supports the findings that an epignathus can directly expand into the cranium, but also presents the possibility that an intracranial lesion can be encapsulated and does not necessarily invade the brain. We believe these rare but important findings will assist gynecologists, neurosurgeons, and pathologists in developing future therapeutic strategies when they are confronted with similar cases. Moreover, although our studied fetus was stillborn, this case provides hope for improved prenatal diagnosis, evaluation,

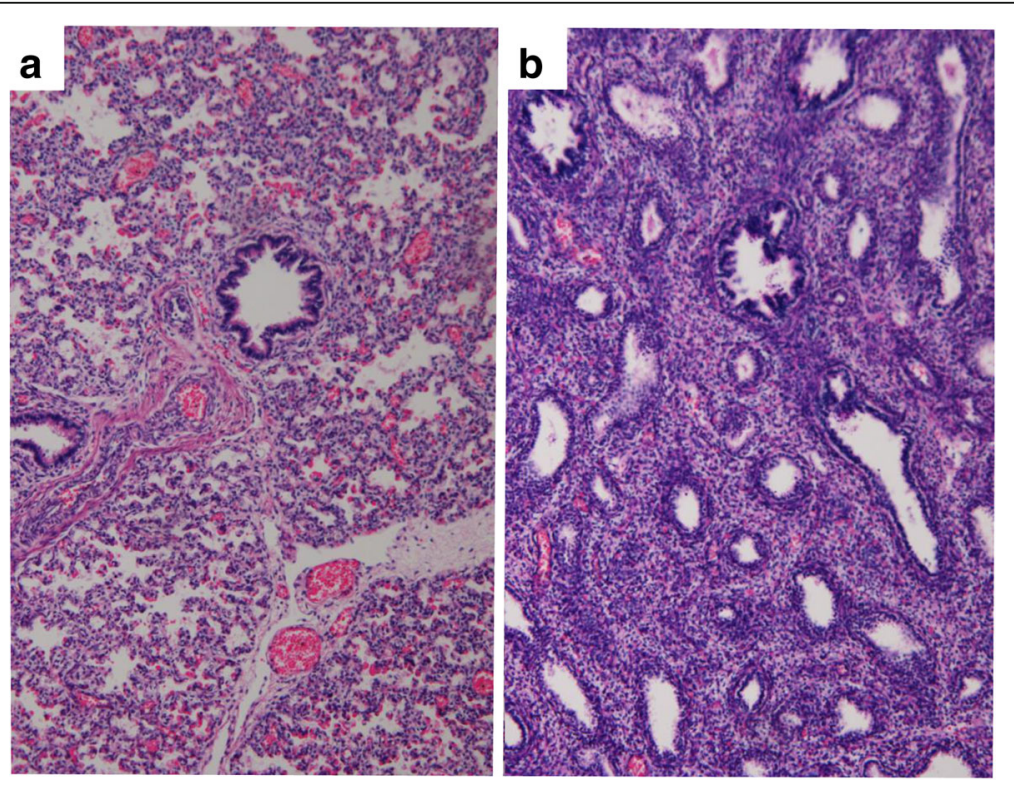

Fig. 6 Microscopic images. a The lungs of the fetus are developed into the saccular stage (hematoxylin and eosin [HE] stain, $\times 100$ ). b The lung seen in the epignathus is in the canalicular stage and is immature compared to the lungs of the fetus (HE stain, $\times 100$ ) 
Table 3 Clinical and pathological summary of our case and 13 previously reported cases of epignathus with intracranial tumor. Earlier cases (1861-1963) were presented in the report by Y. Hosoda [14]

\begin{tabular}{|c|c|c|c|c|c|c|}
\hline Author & year & Mother & Autosite & Epignathus & Connection & Intracranial tumor \\
\hline $\begin{array}{l}\text { Wegelin } \\
{[14]}\end{array}$ & 1861 & para 1 & $\begin{array}{l}6 \text { fetal mo., } \\
\text { m. }\end{array}$ & $\begin{array}{l}8 \times 10 \times 6 \mathrm{~cm} . \text { tridermal, feet } \\
\text { with toes }\end{array}$ & sella turcica \& crista galli & 4 cysts in the base of skull \\
\hline $\begin{array}{l}\text { Breslau \& } \\
\text { Rindfleisch } \\
{[14]}\end{array}$ & 1864 & $\begin{array}{l}28 \text { y-o., para } 1 \\
\text { polyhydroamnion }\end{array}$ & $\begin{array}{l}23-24 \text { fetal } \\
\text { W., f., B.W. } \\
1548 \mathrm{~g}\end{array}$ & $\begin{array}{l}\text { fist-sized, mouth, eyes, } \\
\text { extremities, Foetus in foetu }\end{array}$ & hypophyseal area, 8-10 cm stalk & $\begin{array}{l}\text { tumor with extremities \& } \\
\text { umbilicus }\end{array}$ \\
\hline Arnold [14] & 1870 & 28 y-o., para 3 & $\begin{array}{l}6 \text { fetal mo., } \\
\text { f., B.W. } \\
1550 \mathrm{~g}\end{array}$ & tridermal & $\begin{array}{l}\text { sella turcica, } 1 \mathrm{~cm} \text { in diameter, } \\
\text { consisted of glial tissue }\end{array}$ & $\begin{array}{l}5 \mathrm{~cm} \text { in diameter, reached to } \\
\text { right temporal scale, neuroglial }\end{array}$ \\
\hline Müller [14] & 1881 & no information & $\begin{array}{l}\text { full term, } 6 \\
\text { days } \\
\text { survived }\end{array}$ & $\begin{array}{l}23 \mathrm{~cm} \text { in length, left oral } \\
\text { cavity, broad based, ecto- \& } \\
\text { meso-derm }\end{array}$ & none & $\begin{array}{l}\text { Walnut-sized, right middle } \\
\text { cranial fossa, connective tissue } \\
\text { \& capillaries }\end{array}$ \\
\hline $\begin{array}{l}\text { Schükry } \\
{[14]}\end{array}$ & 1923 & no information & $\begin{array}{l}7 \text { fetal mo., } \\
\text { f., cleft } \\
\text { palate }\end{array}$ & $\begin{array}{l}\text { chestnut-sized, pharynx, } \\
\text { tridermal }\end{array}$ & sella turcica, firm fibrous tissue & $\begin{array}{l}\text { right side of sella turcica, } \\
\text { tridermal }\end{array}$ \\
\hline Kraus [14] & 1929 & no information & $\begin{array}{l}\text { premature, } \\
\text { f., B.L. } 42 \\
\mathrm{~cm}\end{array}$ & $\begin{array}{l}37 \times 30 \mathrm{~mm} \text {, intraoral, } \\
\text { tridermal }\end{array}$ & $\begin{array}{l}\text { craniopharyngeal canal, } 7-8 \mathrm{~mm} \\
\text { in length, } 4.5 \mathrm{~mm} \text { in width }\end{array}$ & $\begin{array}{l}12 \times 18 \times 15 \mathrm{~mm} \text {, sella turcica, } \\
\text { tridermal }\end{array}$ \\
\hline Ehrich [14] & 1945 & $\begin{array}{l}18 \text { y-o., primipara, } \\
\text { polyhydroamnion }\end{array}$ & $\begin{array}{l}5 \text { fetal mo., } \\
\text { still born, f., } \\
\text { B.W. } 1760 \\
\text { g, large } \\
\text { head }\end{array}$ & $\begin{array}{l}5 \times 8 \times 4 \mathrm{~cm} \text {, ecto- } \& \text { meso- } \\
\text { derm, pharynz }\end{array}$ & brain tissue in sphenoid bone & $\begin{array}{l}\text { filling the cranial cavity, } \\
\text { tridermal }\end{array}$ \\
\hline $\begin{array}{l}\text { Hosoda } \\
{[14]}\end{array}$ & 1963 & $\begin{array}{l}26 \text { y-o., gravidae } \\
\text { iv, para } 0\end{array}$ & $\begin{array}{l}36 \text { fetal w., } \\
\text { f., B.W. } \\
1950 \mathrm{~g}\end{array}$ & $\begin{array}{l}6.5 \times 3.5 \times 2.0 \mathrm{~cm} \text {, polypoid } \\
\text { tumor hanging down from } \\
\text { the upper lip, ecto- } \& \\
\text { meso-derm }\end{array}$ & no direct connection & $\begin{array}{l}\text { anterior cranial fossa, } 5 \mathrm{~mm} \\
\text { anterior to the sella turcica, } \\
\text { spherical tumor, } 4 \times 3.5 \times 2.8 \\
\mathrm{~cm} \text {, tridermal }\end{array}$ \\
\hline Smith [15] & 1993 & 30 y-o., para 3 & $\begin{array}{l}29 \text { fetal w., } \\
\text { aborted., f., } \\
\text { B.W. } 1330 \mathrm{~g}\end{array}$ & $\begin{array}{l}3.5 \mathrm{~cm} \text { in diameter, oral } \\
\text { tumor attached to the hard } \\
\text { palate in the midline, } \\
\text { tridermal }\end{array}$ & $\begin{array}{l}\text { tumor was in continuity, via a } \\
\text { narrow defect in the hard palate, } \\
\text { sphenoid bone, third ventricle, } \\
\text { extending to the lateral } \\
\text { ventricles }\end{array}$ & $\begin{array}{l}\text { central tumour mass separating } \\
\text { the temporal lobes, which } \\
\text { progected rostrally between } \\
\text { dilated lateral ventricles, partly } \\
\text { replacing the septum } \\
\text { pellucidum }\end{array}$ \\
\hline Smith [15] & 1993 & $\begin{array}{l}28 \text { y-o., para } 1, \\
\text { polyhydroamnion }\end{array}$ & $\begin{array}{l}18 \text { fetal w., } \\
\text { aborted., f. }\end{array}$ & $\begin{array}{l}2 \mathrm{~cm} \text { in diameter, slightly } \\
\text { gelatinous nodule } \\
\text { protruding ftom the right } \\
\text { upper lip and attached to } \\
\text { the right maxilla, tridermal }\end{array}$ & $\begin{array}{l}\text { narrow cord which traversed the } \\
\text { nasal bones and entered the } \\
\text { cranial cavity in the region of the } \\
\text { pituitary fossa and direct } \\
\text { communication with the mass in } \\
\text { the frontal lobes. }\end{array}$ & $\begin{array}{l}\text { partly cystic, lobular mass } \\
\text { replacing the frontal. } \\
\text { Predominantly neuroglial, with } \\
\text { prominent ependymal rosettes }\end{array}$ \\
\hline $\begin{array}{l}\text { Johnston } \\
{[10]}\end{array}$ & 2007 & no information & $\begin{array}{l}38 \text { fetal w., } \\
\text { m., }\end{array}$ & $\begin{array}{l}4 \times 5 \mathrm{~cm} \text {, midline } \\
\text { oropharyngeal mass } \\
\text { protruding through a cleft } \\
\text { deformity }\end{array}$ & none & $\begin{array}{l}\text { anterior and middle cranial } \\
\text { fossae }\end{array}$ \\
\hline Calda [17] & 2010 & $\begin{array}{l}29 \text { y-o., } \\
\text { primigravida }\end{array}$ & $\begin{array}{l}20 \text { fetal w., } \\
\text { aborted., f., } \\
\text { B.W. } 310 \mathrm{~g}\end{array}$ & $\begin{array}{l}2 \mathrm{~cm} \text { in diameter, lobulated } \\
\text { round vascular mass, visible } \\
\text { trhough the open oral } \\
\text { cavity, tridermal }\end{array}$ & none & $\begin{array}{l}13 \times 10 \times 7 \mathrm{~mm} \text {, neuroepithelial } \\
\text { intracranial cyst }\end{array}$ \\
\hline Wang [12] & 2017 & $\begin{array}{l}31 \text { y-o., } \\
\text { primagravida }\end{array}$ & $\begin{array}{l}17 \text { fetal w., } \\
\text { aborted, } \\
\text { m., } 355 \mathrm{~g}\end{array}$ & $\begin{array}{l}6.7 \times 6.5 \times 5.0 \mathrm{~cm} \text {, } \\
\text { protruding from the right } \\
\text { maxillofacial region, } \\
\text { tridermal }\end{array}$ & directly growing upward & $\begin{array}{l}\text { middle and posterior cranial } \\
\text { fossa, } 3.5 \mathrm{~cm} \text { in diameter, } \\
\text { tridermal }\end{array}$ \\
\hline Our case & 2018 & $\begin{array}{l}32 \text { y-o., } 3 \text { gravida } \\
\text { para } 2\end{array}$ & $\begin{array}{l}27 \text { fetal w., } \\
\text { stillborn, f., } \\
1228 \mathrm{~g}\end{array}$ & $\begin{array}{l}12 \times 6 \times 6 \mathrm{~cm}, 270 \mathrm{~g} \text {, solid and } \\
\text { multicystic tumor, based on } \\
\text { the soft palate and } \\
\text { protruding from mouth }\end{array}$ & $\begin{array}{l}\text { the right side of the sella turcica, } \\
2 \mathrm{~mm} \text { in diameter }\end{array}$ & $\begin{array}{l}\text { middle cranial fossa, capsuled } \\
\text { tumor, } 24 \mathrm{~g} \text {, no direct invasion } \\
\text { to the brain }\end{array}$ \\
\hline
\end{tabular}


and management of potential cases of epignathus with intracranial extension. However, further study of these rare cases is warranted.

\section{Abbreviations}

EXIT: Ex utero intrapartum treatment; MRI: Magnetic resonance imaging

\section{Acknowledgements}

We would like to thank all members of our department for their helpful comments and general support. We would also like to thank Editage (http://www.editage.jp) for English language editing.

\section{Funding}

Not applicable.

\section{Availability of data and materials}

The dataset supporting the findings and conclusions of this case report is included within the article and Tables.

\section{Authors' contributions}

MK performed the autopsy and wrote the manuscript. SY reviewed the case. MS provided ultrasonographic and MRI images. SO provided clinical comments at autopsy. YG, IK, TH, MH, AH and AT contributed to the pathologic diagnosis. All authors have read and approved the final manuscript.

\section{Ethics approval and consent to participate}

Not applicable.

\section{Consent for publication}

Written informed consent was obtained from the parents of the fetus for the publication of this case report and any accompanying images. Copies of the consent forms are available for review by the corresponding author.

\section{Competing interests}

The authors declare that they have no competing interests.

\section{Publisher's Note}

Springer Nature remains neutral with regard to jurisdictional claims in published maps and institutional affiliations.

\section{Author details}

${ }^{1}$ Department of Pathology, Field of Oncology, Graduate School of Medical and Dental Sciences, Kagoshima University, 8-35-1 Sakuragaoka, Kagoshima 890-8544, Japan. ${ }^{2}$ Department of Pathology, Kagoshima University Hospital, 8-35-1 Sakuragaoka, Kagoshima 890-8544, Japan. ${ }^{3}$ Department of Pathology and Laboratory Medicine, Kanazawa Medical University, 1-1 Daigaku,

Uchinada, Kahoku, Ishikawa 920-0293, Japan. ${ }^{4}$ Department of Obstetrics and Gynecology, Kagoshima University Hospital, 8-35-1 Sakuragaoka, Kagoshima 890-8544, Japan. ${ }^{5}$ Department of Pediatric Surgery, Research Field in Medical and Health Sciences, Medical and Dental Area, Research and Education Assembly, Kagoshima University, 8-35-1 Sakuragaoka, Kagoshima 890-8544, Japan.

Received: 18 July 2018 Accepted: 10 December 2018

Published online: 22 December 2018

\section{References}

1. Chauhan DS, Guruprasad Y, Inderchand S. Congenital nasopharyngeal teratoma with a cleft palate: case report and a 7 year follow up. J Maxillofac Oral Surg. 2011;10:253-6.

2. Becker S, Shön R, Gutwald R, Otten JE, Maier W, Hentschef R, et al. A congenital teratoma with a cleft palate: report of a case. Br J Oral Maxillofac Surg. 2007;45:326-7.

3. Benson RE, Fabbroni G, Russell JL. A large teratoma of the hard palate: a case report. Br J Oral Maxillofac Surg. 2009:47:46-9.

4. Isaacs H Jr. II. Perinatal brain tumors: a review of 250 cases. Pediatr Neurol. 2002;27:333-42.

5. $\mathrm{Ng} \mathrm{HN}$, Ong CL. Two case reports of intracranial teratoma diagnosed antenatally. Ann Acad Med Singap. 1993;22:823-5.
6. Ernst LM, Ruchelli ED, Huff DS. Color atlas of fetal and neonatal histology. 1st ed. New York City: Springer; 2011. p. 70-3.

7. Gilbert-Barness E, Spicer DE, Steffensen TS, Oitz JM. Handbook of pediatric autopsy pathology. 2nd ed. New York City: Springer; 2013. p. 67.

8. Schwartz S, Raffel L, Sun CC, Waters E. An unusual mosaic karyotype detected through prenatal diagnosis with duplication of $1 \mathrm{q}$ and $19 p$ and associated teratoma development. Teratology. 1992;46:399-404.

9. Witters I, Moerman P, Louwagie D, Van Assche FA, Migeon BR, Fryns JP. Second trimester prenatal diagnosis of epignathus teratoma in ring $X$ chromosome mosaicism with inactive ring $X$ chromosome. Ann Genet. 2001;44:179-82.

10. Staboulidou I, Miller K, Göhring G, Hillemanns P, Wüstemann M. Prenatal diagnosis of an epignathus associated with a 49,XXXXY karyotype--a case report. Fetal Diagn Ther. 2008;24:313-7.

11. Dakpé S, Demeer B, Cordonnier C, Devauchelle B. Emergency management of a congenital teratoma of the oral cavity at birth and three-year follow-up. Int J Oral Maxillofac Surg. 2014;43:433-6.

12. Wang $A C, G u Y Q$, Zhou XY. Congenital giant epignathus with intracranial extension in a fetal. Chin Med J. 2017;130:2386-7.

13. Carvalho CHP, Nonaka CFW, Elias CTV, Matheus RCS, Dias RMB, Souza LB, et al. Giant epignathus teratoma discovered at birth: a case report and 7year follow-up. Braz Dent J. 2017;28:256-61.

14. Hosoda Y. A case of epignathus associated with intracranial teratoma in a new-born infant: with a review of related Japanese literature. Keio J Med. 1963;12:61-75.

15. Smith NM, Chambers SE, Billson VR, Laing I, West CP, Bell JE. Oral teratoma (epignathus) with intracranial extension: a report of two cases. Prenat Diagn. 1993;13:945-52.

16. Johnston JM, Vyas NA, Kane AA, Molter DW, Smyth MD. Giant intracranial teratoma with epignathus in a neonate. J Neurosurg. 2007;106:232-6.

17. Calda P, Novotná M, Cutka D, Břešták M, Hašlik L, Goldová B, et al. A case of an epignathus with intracranial extension appearing as a persistently open mouth at 16 weeks and subsequently diagnosed at 20 weeks of gestation. $J$ Clin Ultrasound. 2011;39:164-8.

\section{Ready to submit your research? Choose BMC and benefit from:}

- fast, convenient online submission

- thorough peer review by experienced researchers in your field

- rapid publication on acceptance

- support for research data, including large and complex data types

- gold Open Access which fosters wider collaboration and increased citations

- maximum visibility for your research: over 100M website views per year

At BMC, research is always in progress.

Learn more biomedcentral.com/submissions 